\title{
Psychiatric assessment of child victims of sexual abuse by Ham A and D Scale: A Descriptive Study
}

Soumeek Chowdhuri, Tutor, Department of Forensic and State Medicine, Calcutta National Medical College, Kolkata, India.

Paramita Ray, Associate Professor, Institute of Psychiatry (Centre of excellence), IPGMER and SSKM hospital, Kolkata, India.

Parthapratim Mukhopadhayay, Professor \& Head, Dept of FSM, Burdwan Medical College, Burdwan, India

Citation: Chowdhuri S, Ray P, Mukhopadhayay P. Psychiatric assessment of child victims of sexual abuse by Ham A and D Scale: A Descriptive Study. Int J Eth Trauma Victimology 2019; 5(1):26-33.

doi.org/10.18099/ijetv.v5i1.4.

\section{Article history}

Received: Feb 22, 2019

Received in revised form: Sept 14, 2019

Accepted: Sept 21, 2019

Available online: Nov 10, 2019

Corresponding author

Soumeek Chowdhuri

Tutor, Department of Forensic and State

Medicine, Calcutta National Medical

College, Kolkata, India.

Phone: +919007580064

Email: smk.kgp@gmail.com

\section{Abstract}

Background

In today's world man finds himself exposed to the temptations of (This entire sentence is not objective, scientific terminology) (These crimes are not limited to TODAY's world, the perpetrator is not always a man, and evil is not a scientific subject to be included in a scholarly paper, it is subjective to individual beliefs and laws).

A movement should have been augmented to fight against these (do not use dramatic subjective terms) societal crimes, which forms a sort of mental purge for those so inclined to take advantage of their positions of trust. Child abuse has historically been a common offence against children without sufficient social and legal sanctions throughout the world. To deal with child sexual abuse cases while treating the victims, it's necessary to assess the patient's psychiatric health. The victims were examined after obtaining informed consent from the child or from their guardian.

Results

The patient's psychiatric health was determined by the Hamilton Scale for depression and anxiety. The total number of cases was 52. Of the 52 cases 33 patients (i.e. $63.5 \%$ of the cases) consented to undergo medical examination. 19 victims (36.5\%) did not give their consent for their medical examination. The mean Hamilton A score for anxiety was 19.39 and mean Hamilton D score for depression was 28.81 .

Conclusions

When the accused is known to the victim most cases are associated with severe or very severe degree of depression; and moderate or severe anxiety. After completing a detail study of the violations of minor girls it is concluded that it would be beneficial for the global society to take initiatives to minimize the incidence of such acts.

Keywords: Child abuse; Hamilton Scale; depression anxiety; forensic psychiatry.

(C) IJETV. All rights reserved

\section{Introduction}

Child sexual abuse is an alarming reality and is being increasingly reported globally. A universal preventative movement should have been augmented to fight against these destructive crimes against children throughout all societies.
Those who commit these crimes often develop a type of mental purge to rationalize their actions while taking advantage of their positions of trust. Child sexual abuse has become a common detestable offence. To deal with child sexual abuse 
cases, while treating the victims, it is necessary to assess their psychiatric health. The police personnel receiving a report of sexual abuse of a child are given the responsibility of making urgent arrangements for the care and protection of the child while obtaining emergency medical treatment, and placing the child in a shelter home if necessary. Official police documentation provides guidelines for the Special Court to determine an appropriate amount of compensation to be paid to a child who has been sexually abused. This money can be used for the patient's medical treatment and rehabilitation. Apart from the role of police and the court, the role of medical professionals is largely felt. Pediatricians and allied medical professionals are often the first point of contact with abused children and their families. Also, to give proper emergency medical treatment and provide rehabilitation, it is necessary to assess the patient's mental health. In this regard, the Hamilton study designed to assess the mental health of sexually abused children in a developing country was essential. Laws against child sexual abuse vary by country based on the legal definition of who is a child and what constitutes child sexual abuse. Most countries employ some form of age of consent with. Sexual contact with an underage person being criminally penalized. As the age of consent regarding sexual behavior varies from country to country, so too do definitions of child sexual abuse. An adult's sexual intercourse with a minor below the legal consent may sometimes be referred to as statutory rape, based on the principle that any apparent consent by a minor could not be considered legal consent (1).

The United Nations Convention on the Rights of the Child (CRC) is an international treaty that legally obligates nations to protect children's rights. Articles 34 and 35 of the CRC require states to protect children from all forms of sexual exploitation and sexual abuse. This includes outlawing the coercion of a child to perform sexual activity, the prostitution of children, and the exploitation of children in creating pornography. States are also required to prevent the abduction, sale, or trafficking of children. As of December 2014, 195 countries have ratified the Convention, including every member of the United Nations except the United States and South Sudan (2) .

\section{In the United States}

Child sexual abuse has been recognized specifically as a type of child maltreatment in U.S. federal law since the initial Congressional hearings on child abuse in 1973. Child sexual abuse is illegal as under federal and state law. Although the specifics of child sexual abuse laws vary throughout the states, but certain features are common to all states (3).

\section{In India}

The Protection of Children Against Sexual Offences Act, 2012 regarding child sexual abuse has been passed by the both the houses of the Indian Parliament (4) and came into force from 14 November 2012 (5).

\section{In South Africa}

The South African laws on sexual offences was codified in the 2007 Criminal Law (Sexual Offences and Related Matters) Amendment Act. Chapter 3 of the act deals with sexual offences against children. The act criminalizes:

- Acts of sexual penetration with a child (statutory rape)

- Other sexual acts with a child (statutory sexual assault)

- Exploitation of children in prostitution

- Sexual grooming of children

- Showing pornography to children

- Using children in child pornography

- Compelling children to witness sexual acts

- Indecent exposure to children

The act establishes a National Register for Sex Offenders which lists people convicted of sexual offences against children and the mentally disabled.

\section{In the United Kingdom}

The United Kingdom rewrote its criminal code in the Sexual Offences Act of 2003. This Act includes definitions and penalties for child sexual abuse offences, and (relating to offences) applies to England and Wales and Northern Ireland. The Scottish Law Commission published its review of rape and sexual offences in December 2007, which includes a similar consolidation and codification of child sexual abuse offences in Scotland.

\section{In Zambia}

A recent June 30, 2008 landmark decision by judge, Philip Musonda, of the Zambian High Court gave a minor girl-student 45 million Zambian Kwacha in awards after her teacher was charged and with statutory rape. This is the first case of its kind for a minor to win against a person of authority in the nation of Zambia. The Hamilton study examined the relationship between child sexual abuse (CSA) and subsequent onset of psychiatric disorders, accounting for other childhood adversities, CSA type, and chronicity of the abuse. 
The study design was of cross-sectional type. The study included victims of sexual assault/abuse under 18 years of age who brought for examination. after age estimation Victims that are found to be over 18 years will be excluded for often it is seen that there is overstatement of age in these cases. Two standard psychiatric scales have been used for this study. This was done by using Hamilton D scale for depression and Hamilton A scale for anxiety.

The Hamilton Rating Scale for Depression (HRSD) has been considered the gold standard for assessing severity of depression and is widely used in research. The HRSD has several versions, with the number of items employed ranging from 17 to 28. The 17-item version is the most commonly used and contains somatic and suicidal ideation items. The questions are more likely understood by semiliterate populations and can be applied easily without an in-house psychiatrist.

The HAM-A was the first rating scale to be published and is available in the public domain (meaning anyone can download and use it). It is a 14-domain practitioner observation-based assessment has been shown and continues to serve as a useful tool within both a clinical and research setting. After several decades of minimal use, a significant resurgence of use of the HAM-A over the last twenty years provides over 900 references in total using a gross bibliometric method (6). The simple, one-page observation questionnaire includes fourteen different domains, which consist of distinctive phrases and feeling associated with each domain. Inasmuch, it provides an indexed score which can be tracked serially across visits and compared to others indicating good intra subject and inter subject reliability. These domains can be easily discussed with the patient and allow a natural conversation between practitioner and patient which is not necessarily a hallmark of similar tools.

Since the objective of this study is to provide a screening before the victim can be sent for specialist psychiatric treatment it was found that the above scales are easier to apply and effective in the study population. (do not refer to the authors in $1^{\text {st }}$ person)

\section{Hamilton Depression Rating Scale (HDRS)}

The HDRS (also known as the Ham-D) is the most widely used clinician-administered depression assessment scale. The original version contains 17 items (HDRS17) pertaining to symptoms of depression experienced over the past week.
Although the scale was designed for completion after an unstructured clinical interview, there are now semi-structured interview guides available. The HDRS was originally developed for hospital inpatients, thus the emphasis on melancholic and physical symptoms of depression. A later 21-item version (HDRS21 included 4items intended to subtype the depression, but which are sometimes, incorrectly, used to rate severity.

\section{Scoring}

Methods for scoring varies by version. For the HDRS17, a score of 0-7 is generally accepted to be within the normal range (or in clinical remission), while a score of 20 or higher (indicating at least moderate severity) is usually required for entry into a clinical trial.

Versions The scale has been translated into a number of languages including French, German, Italian, Thai, and Turkish. There is an Interactive Voice Response version (IVR), a Seasonal Affective Disorder version (SIGH-SAD, seepage 55), and a Structured Interview Version (HDS-SIV). Numerous versions with varying lengths include theHDRS17, HDRS21, HDRS29, HDRS8, HDRS6, HDRS24, and HDRS7.

\section{Hamilton Anxiety Rating Scale (HAM-A)}

Rating Clinician-rated Administration time 10-15 minutes. The main purpose is to assess the severity of symptoms of anxiety in adult populations, adolescents and children.

\section{Commentary}

The HAM-A was one of the first rating scales developed to measure the severity of anxiety symptoms and is still widely used today in both clinical and research settings. The scale consists of 14 items, each defined by a series of symptoms, and measures both psychic anxiety (mental agitation and psychological distress) and somatic anxiety (physical complaints related to anxiety). Although the HAM-A remains widely used as an outcome measure in clinical trials and the reported levels of interrater integrated reliability for the scale to be acceptable. Scoring each item is scored on a scale of 0 (not present) to 4 (severe), with a total score range of $0-56$. Consent was taken from the patients and their legal guardian for the use of their data for research purposes. Ethical committee clearance was taken from Institutional Ethics Committee.

\section{Results}

Total number of cases was 52 . Of the 52 cases 33 (i.e. $63.5 \%$ of the cases) consented to undergo Int J Eth Trauma Victimology 2019; 5(1):28. 
medical examination. However, 19 victims (36.5\%) did not give their consent for the medical examination. Amongst them the maximum age was 18 years. The minimum was 3 years of age and the mean age was 13.15 years. Majority (63.3\%) cases belonged to low socioeconomic strata of the society, $33.33 \%$ of the victims were from middle socioeconomic strata of the society and only one case was reported from high socioeconomic status. The study population $23(44.23 \%)$ were from the general caste whereas 29 i.e. $55.8 \%$ (16 Scheduled castes, 8 scheduled tribes, 6 OBCs) and were from the backward castes. This is important in the context of our study because the backward caste is the most neglected group in our society. Majority of cases were from high school (11 cases, $37.93 \%)$ followed by $27.59 \%$ who were school dropouts and $10.34 \%$ were from primary school.

The mean Hamilton A score for anxiety was 19.39 and the mean Hamilton $D$ score for depression was 28.81 (shown in Table 1). When the accused is known to the victim, most cases are associated with severe or very severe degree of depression. The chi-square tests were used to show the $p$ value for the association between relation with accused and degree of depression which is 0.579 , which is not of high significance. However, this may be misleading due to the fact that a smaller number of study subjects were used and had there been a larger sample size, a higher significance would have resulted. Also, when the accused is known to the victim (i.e. either known or semiacquaintance or relative) it is associated with moderate or severe anxiety in 14 cases. The chisquare tests gave the $p$ value for this correlation between anxiety and relationship with accused as 0.693 , which could have been better with larger sample size.

Of the 33 victims who were examined, suicidal tendency was seen in $15.2 \%$ of the patients (Chart 1). Those who are victims of sexual assault (hymen tear) $48.39 \%$ were associated with severe degree of anxiety. The majority of cases reporting on first day for examination presented with moderate or severe anxiety. The maximum reporting was seen on the first day. (first day of assault or first day of examination?

(Chart 3) shows correlations between degrees of depression with socioeconomic status. This indicates that victims from a lower socio economic status showed a more severe degree of depression. In those whom hymen injury was absent the degree of anxiety (9.68\%) was much less. The chi square test shows that in victims of sexual assault the $p$ value of association with anxiety was 0.006 .

The $p$ value of the chi square test showing correlation between depression and suicidal tendency is 0.104 . Of this $15.2 \%$ of the victims, the majority of girls who had suicidal tendency were in the age group of 12-17 years (Chart 8). Suicidal tendency was associated in cases mostly in those in whom severe depression was demonstrated (chart 7). The majority with moderate and severe degree of anxiety were at higher risk for attempting suicide (Chart 9).

The degree of depression, the degree of anxiety, the age of the person and who the accused is and how is he related to the victim?

\section{Discussion}

The time interval between the incident and the examination varied widely in the sample making it difficult to comment on the temporal relationships of sexual assault and the severity of the post traumatic symptoms. This is in agreement with a study conducted earlier at this center (7). The findings of this study are congruent with previous studies. The refusal rate was higher in the backward portion of the society showing that they were more traumatized and afraid of exposure in the society (8) (9). Rapes by strangers have been shown to involve more violence and trauma (Katz and Mazur, 1979) and the study compares 21 rape attacks where the assailant was known to the victim with 30 attacks where the assailant was a stranger. As per the classification based on scores (Kaplan $10^{\text {th }}$ edition) the total number of victims are classified as mild depression $1.9 \%$, moderate depression $1.9 \%$ severe depression $3.8 \%$ very severe depression $55.8 \%$. In an earlier study by Kanwar et al. in 2013 although anxiety has been proposed to be a potentially modifiable risk factor for suicide, research examining the relationship between anxiety and suicidal behaviours has demonstrated mixed results. As per Resnick 1999, for women, the odds of attempting suicide were 3 to 4 times greater when the first reported sexual assault occurred prior to age 16 years compared to 16 years or older (10). Curtis (1974) studied the various aspects of criminal violence and observed that violence against women remained as a disturbing trend worldwide(11). This finding is also similar in our study.

According to a report of Los Angeles had the highest rate of rape (54.5 per 1 lakh population) among the standard and metropolitan areas of the United States (12). Rose (1974) has discussed the 
various forms of urban violence Accordingly, urban areas minor girls are often the victims of violence like rape and kidnapping. In our study when the accused is known to the victim i.e. either known or semi-acquaintance or relative it is associated with moderate or severe anxiety in 14 cases (13). The chi-square tests gave the $p$ value for this correlation between anxiety and relationship with accused as 0.693 , which could have been better with larger sample size.

The purpose of the study was to determine if patients with a history of major depressive episode and co morbid posttraumatic stress disorder (PTSD) have a higher risk for suicide attempt and differ in other measures of suicidal behavior, compared to patients with major depressive episode but no PTSD. In addition, to explore how PTSD co morbidity might increase risk for suicidal behavior in major depressive episode, the authors investigated the relationship between PTSD, cluster B personality disorder, childhood sexual or physical abuse, and aggression/impulsivity.

As suggested by Fried 2015 the pervasive use of sum-scores to estimate depression severity has obfuscated crucial insights and contributed to the lack of progress in key research areas such as identifying biomarkers and more efficacious antidepressants. The analysis of individual symptoms and their causal associations offers a way forward (14).

It was observed in the present study that when the accused is known to the victim then most cases are associated with severe or very severe degree of depression. This finding is in variance to some degree with findings of Ullmaan et al in 2006 in western countries where it was seen that Positive social reactions do not vary according to the victim-offender relationship, but stranger victims report more negative social reactions from others than do victims of acquaintances or romantic partners (15). Assaults by strangers and relatives are associated with more posttraumatic stress disorder (PTSD) symptoms than assaults by acquaintances and romantic partners. As expected, survivors' social cognitive responses to rape and social reactions from support providers are stronger correlates of PTSD symptoms than demographic or assault characteristics in general, but correlates vary across victim-offender relationship groups (15). This based on the findings of our study, we also hypothesize that knowing the accused increases the chances of social stigma and most likely leads to increased anxiety in the victims.
Ullman (1993) while analyzing the psychological symptoms measures showed that sexual distress was more common for women attacked by intimates, fear/anxiety was more common for women assaulted by strangers and depression did not vary according to the victim-offender relationship (16). The present study revealed that when the accused is known to the victim i.e. either known or semi acquaintance or relative it is associated with moderate or severe anxiety in 14 cases. This difference can be attributed to the difference in social and cultural values as well as family structure that is different in the Indian society in comparison to western countries where these studies were conducted. In an earlier study by Kanwar et al in 2013 although anxiety has been proposed to be a potentially modifiable risk factor for suicide, research examining the relationship between anxiety and suicidal behaviours has demonstrated mixed results (17). PTSD is frequently co morbid with major depressive episode, and their co-occurrence enhances the risk for suicidal behavior. A higher rate of co morbid cluster B personality disorder appears to be a salient factor contributing to greater risk for suicidal acts in patients with a history of major depressive episode who also have PTSD, compared to those with major depressive episode alone (18). During the past 20 years, researchers have documented the widespread problem of rape in American society. Approximately one in four women are raped in their adult lifetime, which causes severe psychological distress and long-term physical health problems. The impact of sexual assault extends far beyond rape survivors as their family, friends, and significant others are also negatively affected. Moreover, those who help rape victims, such as rape victim advocates, therapists, as well as sexual assault researchers, can experience vicarious trauma. Future research and advocacy should focus on improving the community response to rape and the prevention of sexual assault (19).

This study on the victims examined under POSCO 2012 act showed that suicidal tendency was associated in cases mostly in those in whom severe depression was demonstrated. The majority of girls who had suicidal tendency were in the age group of 12- 17 years. Analyzing the relationship between anxiety and suicidal tendency in the victims it was seen that Majority with moderate and severe degree of anxiety were at higher risk for attempting suicide. This finding is similar to an earlier study conducted in the western population(10). For women, the odds of attempting suicide was 3 to 4 times greater when 
the first reported sexual assault occurred prior to age 16 years compared to 16 years or older. Sexual assault is associated with an increased lifetime rate of attempted suicide. In women, a history of sexual trauma before age 16 years is a particularly strong correlate of attempted suicide. (Jonathan et al 1996). Suicidal behavior to be significantly associated with the presence of insomnia, parasomnias, and sleep-related breathing disorders, but not hypersomnia. Another systematic review and meta-analysis suggested that in patients with psychiatric diagnoses, sleep disturbances are associated with the increased risk of suicidal behaviors (20). The present study showed a similar finding to the study. Bourque et al (1983) have discussed the attributes of suicide in females. They have noted that being of sensitive nature; the victims of violence are more prone to depression and other related problems of maladjustment (21).

Ladame (1982) reviewed the epidemiology of suicide in adolescents and noted that sexual violence is the major contributory factor towards the problem (22). Brodskyu and Walker (1976) were also the opinion that suicide and sexual assault are closely related. Contrary to the observations of earlier workers on the consequence of rape, there was no case of acute stress related- disorder. Acute polymorphic psychosis, which is common with cases of sexual violence, was not found in this series. This may explained by the fact that majority of the victims were not subjected to any form of true violence (physical over experiencing phenomena, numbing, detachment, amnesia (dissociative experience) or panic disorder (23). Elklit (2013) in a study conducted in 2013 showed that Posttraumatic stress disorder (PTSD) is common in the aftermath of rape and other sexual assault, but the risk factors leading to PTSD following rape have been shown to differ from those related to PTSD following nonsexual assault. Regression analyses showed that relationship with the assailant, number of assailants, the nature of the assault, perceived positive social support, support satisfaction, feeling let down by others, and prior exposure to sexual trauma did not significantly predict PTSD severity at the final level of analysis (24). In accordance with suggestions by Dancu, Riggs, Hearst-lkeda, and Shoyer (1996), it is suggested that this is partly caused by a very high degree of traumatization in the sample. Instead, previous nonsexual traumatic experiences and negative affectivity accounted for $30 \%$ of the variance in PTSD severity these findings suggest that although sexual assault is associated with a high degree of PTSD severity, prior nonsexual victimization and high levels of negative affectivity appear to further increase the vulnerability toward developing symptoms of assault-related PTSD. Recovery from rape trauma is a deeply personal and highly individualized journey. As knowledge of the pathophysiology of PTSD improves, more effective medications are developed to treat and manage the biological aspects of this disorder. Psychological therapies are available to assist survivors in their recovery. The number of rape prevention centers and education programs are on the rise with aims to debunk rape myths, change victim-blaming attitudes and de stigmatize the subject. One of the most important aspects in assisting the recovery process is empowering the survivor and putting control back into their hands. The three-treatment modalities for the biological, psychological, and sociological impacts should Keeping in mind the shortcomings of this study, that we had a smaller number of study samples, we would recommend to conduct more studies in this area with a larger number of study subjects and the results of the study to be extrapolated to give a basic guideline to the training emergency physician in relation to the psychiatric condition of the victims (25).

The present study had its own limitations in that it was based on the interview with minor victim girls. It can be regarded as a descriptive study. The girls could not be verified. Some communication problems could not be avoided in these circumstances. Moreover, owing to small number of cases available during the stipulated period of study, conclusive interpretations could not be made. This study being the first of its kind being conducted at this centre, larger multi centric studies at regional and national level needs to be done to substantiate the hypothesis that that was generated by the present study.

\section{Conclusion}

After completing a detail study of sexual violations on minor girls it is concluded that it would be beneficial for the society to take initiative to minimize the incidence of such acts. Hence some recommendations are being suggested in this particular arena.

1. Special drive should be made for further research and exploration of this grave problem and interrelated factors.

2. Behavioural pattern of adolescents should be studied to reduce the number of such cases of sexual violence. 
3. A follow-up study of these cases needs to be undertaken to evaluate the long term effects on health.

4. Social values and morality of people should be changed so that women are given due respect in our society.

5. Continuous drive is to be made to promote literacy. By this the sufferer may have some opportunity to prepare for suitable livelihood in future. Proper stress should be laid on the efficacy of health education emphasizing prevention of sexually transmitted diseases.

6. The socioeconomic standard of the families of the patients need to be uplifted by various integrated means to combat the ailments.

7. The role of the media cannot be ignored.

8. Exemplary punishment should be awarded to the offenders of atrocities on minor girls. Law enforcing agencies should adopt ways and means of investigations which would be

1. Blacks Law Dictionary 8th Edition by Bryan A Garner [Internet]. [cited 2019 Oct 30]. Available from: https://www.powells.com/book/blackslaw-dictionary-8th-edition-9780314151995

2. United Nations Treaty Collection. 2009.

3. Child Abuse and Neglect, Children's Bureau, U.S. Department of Health and Human Services.).

4. Parliament passes bill to protect children from sexual abuse. NDTV; 2012.

5. The Hindu. 2012 Nov 15;

6. Bruss GS, Gruenberg AM, Goldstein RD, Barber JP. Hamilton Anxiety Rating Scale Interview guide: joint interview and test-retest methods for interrater reliability. Psychiatry Res. 1994;53(2):191-202.

7. Mukhopadhyay P, Singh O. Psychiatric assessment of victims of sexual assault:Burdwan Medical College, Burdwan. J IndianAcad Forensic Med. 2010;31(3).

8. Mukhopadhyay P. Medico legal study of the victims of Sexual Assault. J Indian Acad Forensic Med. 2003;25(1):27-31.

9. Mukhopadhyay PP, Karmakar RN, Sarkar D. Decadal change in patern and demography of female victims of sex offence examined at Burdwan Medical College, Burdwan, West Bengal, India: Myth versus reality. Indian J Forensic Med Toxicol. 2010;4(1).

10. Resnick H, Acierno R, Holmes M, Kilpatrick DG, Jager N. Prevention of post-rape appropriate for the victims' age and mentality. This is because they are always expected to give evidence in a court of law and have to go through utter humiliation and stress involved in the legal procedure.

9. After rescue proper rehabilitation must be assured.

10. Various organizations should increase efforts to motivate the public regarding the dangers of the child sexual abuse and the resultant health related problems.

11. The results of the study can be extrapolated to provide basic guidelines for training emergency physicians and nurses in relation to traumatic psychiatric conditions which must be documented.

\section{References}

psychopathology: Preliminary findings of a controlled acute rape treatment study. J Anxiety Disord. 1999;13(4):359-370.

11. Curtis L. Criminal violence. Toronto: Lexington Books D.C. Helath and Co.; 1974. 35-37 p.

12. Federal Bureau of Investigation; 1974.

13. Rose DS. "Worse than death": Psychodynamics of rape victims and the need for psychotherapy. Am J Psychiatry. 1986;

14. Fried El, Nesse RM. Depression sum-scores don't add up: why analyzing specific depression symptoms is essential. BMC Med. 2015;13(1):72.

15. Ullman SE, Filipas HH, Townsend SM, Starzynski LL. The role of victim-offender relationship in women's sexual assault experiences. J Interpers Violence. 2006;21(6):798-819.

16. Ullman SE, Siegel JM. Victim-offender relationship and sexual assault. Violence Vict. 1993;8(2):121.

17. Kanwar A, Malik S, Prokop LJ, Sim LA, Feldstein $D$, Wang $Z$, et al. The association between anxiety disorders and suicidal behaviors: A systematic review and meta-analysis. Depress Anxiety. 2013;30(10):917-929.

18. Oquendo $\mathrm{M}$, Brent DA, Birmaher B, Greenhill L, Kolko D, Stanley B, et al. Posttraumatic stress disorder comorbid with major depression: factors mediating the association with suicidal behavior. Am J Psychiatry. 2005;162(3):560566. 
19. Campbell R, Sefl T, Barnes HE, Ahrens CE, Wasco SM, Zaragoza-Diesfeld Y. Community services for rape survivors: Enhancing psychological well-being or increasing trauma? J Consult Clin Psychol. 1999;67(6):847.

20. Malik S, Kanwar A, Sim LA, Prokop LJ, Wang Z, Benkhadra $\mathrm{K}$, et al. The association between sleep disturbances and suicidal behaviors in patients with psychiatric diagnoses: a systematic review and meta-analysis. Syst Rev. 2014;3(1):18.

21. Bourque L. Attributes of suicide in females, Suicide, Life threat behave. Summer. 1983;13(2):123-38.

22. Ladame $\mathrm{F}$, Jeanneret $\mathrm{O}$. Suicide in adolescence: some comments on epidemiology and prevention. J Adolesc. 1982;5(4):355.

23. Brodsky S, Walker M. Sexual Assault. Toaronto: Lexinton Books; 1976. 92-98 p.

24. Elklit A, Christiansen DM. Risk factors for posttraumatic stress disorder in female helpseeking victims of sexual assault. Violence Vict. 2013;28(3):552-568.

25. Dancu CV, Riggs DS, Hearst-Ikeda D, Shoyer BG, Foa EB. Dissociative experiences and posttraumatic stress disorder among female victims of criminal assault and rape. J Trauma Stress. 1996;9(2):253-267. 